\title{
Steady-state aerosol distributions in the extra-tropical, lower stratosphere and the processes that maintain them
}

\author{
J. C. Wilson ${ }^{1}$, S.-H. Lee ${ }^{2}$, J. M. Reeves ${ }^{1}$, C. A. Brock ${ }^{3}$, H. H. Jonsson ${ }^{4}$, B. G. Lafleur ${ }^{1}$, M. Loewenstein ${ }^{5}$, J. Podolske ${ }^{5}$, \\ E. Atlas ${ }^{6}$, K. Boering ${ }^{7}$, G. Toon ${ }^{8}$, D. Fahey ${ }^{3}$, T. P. Bui ${ }^{5}$, G. Diskin ${ }^{9}$, and F. Moore ${ }^{10}$ \\ ${ }^{1}$ Department of Mechanical and Materials Engineering, University of Denver, Denver, CO, 80208-0177, USA \\ ${ }^{2}$ Department of Chemistry, Williams Hall, Kent State University, Kent, OH 44240, USA \\ ${ }^{3}$ NOAA ESRL CSD, 325 Broadway, Boulder, CO 80305, USA \\ ${ }^{4}$ CIRPAS/Naval Postgraduate School, Marina, CA 93933, USA \\ ${ }^{5}$ NASA Ames Research Center, MS 245-5, Moffett Field, CA 94035-1000, USA \\ ${ }^{6}$ University of Miami, 4600 Rickenbacker Causeway, Miami, FL 33149, USA \\ ${ }^{7}$ Department of Chemistry, Room 419 Latimer Hall, University of California, Berkeley, CA 94720-1460, USA \\ ${ }^{8}$ Jet Propulsion Laboratory, California Institute of Technology, 4800 Oak Grove Drive, Pasadena, Ca 91109, USA \\ ${ }^{9}$ Chemistry and Dynamics Branch, MS 483, NASA Langley Research Center, Hampton, VA 23681, USA \\ ${ }^{10}$ NOAA ESRL GMD, 325 Broadway, Boulder, CO 80305, USA
}

Received: 12 December 2007 - Published in Atmos. Chem. Phys. Discuss.: 22 February 2008

Revised: 12 August 2008 - Accepted: 10 September 2008 - Published: 17 November 2008

\begin{abstract}
Measurements of aerosol, $\mathrm{N}_{2} \mathrm{O}$ and OCS made in the Northern Hemisphere below $21 \mathrm{~km}$ altitude following the eruption of Pinatubo are presented and analyzed. After September 1999, the oxidation of OCS and sedimentation of particles in the extra-tropical overworld north of $45 \mathrm{~N}$ are found to maintain the aerosol in a steady state. This analysis empirically links precursor gas to aerosol abundance throughout this region. These processes are tracked with ageof-air which offers advantages over tracking as a function of latitude and altitude. In the extra-tropical, lowermost stratosphere, normalized volume distributions appear constant in time after the fall of 1999. Exchange with the troposphere is important in understanding aerosol evolution there. Size distributions of volcanically perturbed aerosol are included to distinguish between volcanic and non-volcanic conditions. This analysis suggests that model failures to correctly predict OCS and aerosol properties below $20 \mathrm{~km}$ in the Northern Hemisphere extra tropics result from inadequate descriptions of atmospheric circulation.
\end{abstract}

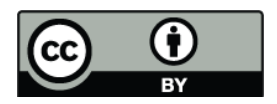

Correspondence to: J. C. Wilson (jwilson@du.edu)

\section{Introduction}

\subsection{Importance of stratospheric aerosol}

Stratospheric aerosol hosts heterogeneous reactions that occur in proportion to the available aerosol surface area and impact the abundance of ozone and other species (Fahey et al., 1993; Wilson et al., 1993; Wennberg et al., 1994). Aerosol also scatters some incoming solar radiation back into space. Artificial enhancement of the stratospheric aerosol has been suggested as a way to counteract the impact of greenhouse gas emissions (Wigley, 2006). Accurate modeling of stratospheric aerosol is important for predicting the recovery of ozone (Solomon et al., 1996) and for evaluating geoengineering responses to climate change.

\subsection{Volcanic and non-volcanic aerosol}

Observations of the stratospheric aerosol over the last several decades reviewed by Hamill and Brogniez (2006) show that volcanic injections have enhanced stratospheric aerosol loading by orders of magnitude over the background levels. Crustal and sulfate particles dominated samples of aerosol particles collected in the lower stratosphere following large eruptions (Sheridan et al., 1992; Overbeck et al., 1983). Measurements of size distributions in the lower stratosphere show that in some locations mean particle

Published by Copernicus Publications on behalf of the European Geosciences Union. 


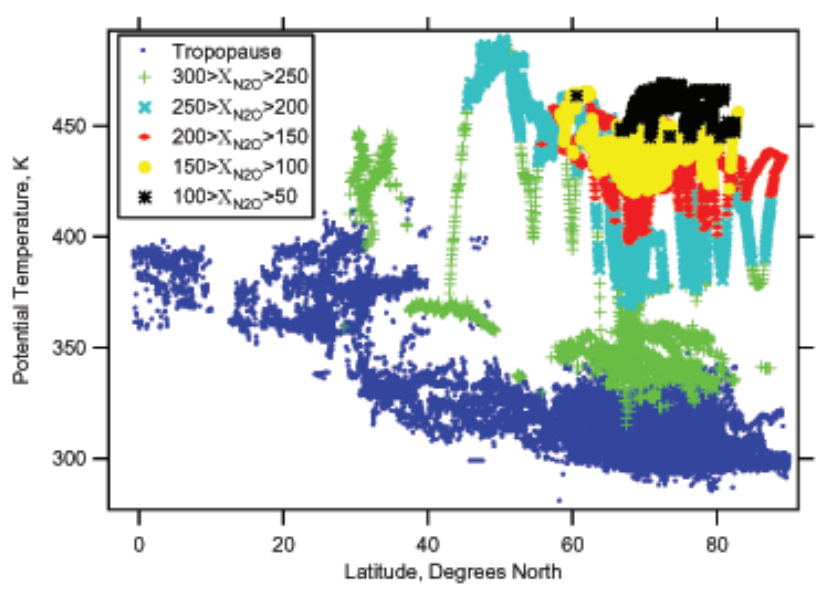

Fig. 1. Location of measurements of non-volcanic aerosol made after September 1999. Location of the tropopause for measurements made from 1992 to 2004 in the Northern Hemisphere.

diameters increased from less than $200 \mathrm{~nm}$ prior to the eruption of Mt. Pinatubo in 1991 to about $800 \mathrm{~nm} 8$ months later (Wilson et al., 1993). In collections of particles with diameters larger than approximately $30 \mathrm{~nm}$ made 23 months after the eruption of Mount Pinatubo, sulfate particles dominated (Sheridan et al., 1994) as expected following the massive injection of sulfur gases that are converted to particulate matter by chemistry in the atmosphere.

The aerosol loadings decay with time following volcanic injections. Observations suggesting a persistent, nonvolcanic stratospheric aerosol are reviewed by Deshler and Anderson-Sprecher (2006) and Hamill and Brogniez (2006) who suggest that a steady-state was established around or after 1997 following the decay of the perturbation caused by the massive eruption of Mt. Pinatubo in 1991.

The life-cycle of stratospheric particles in the absence of volcanic injections involves air motions and aerosol dynamics (Hamill et al., 1997). Particles and aerosol precursor gases enter the stratosphere. Atmospheric chemistry converts the precursor gases to condensable molecules that condense and add aerosol mass (gas-to-particle conversion). Coagulation and condensation of condensable vapors alters the size of particles and gravitational sedimentation redistributes aerosol in the downward direction. Particles are removed from the stratosphere by sedimentation and as air returns to the troposphere. Although non-volcanic stratospheric particles exhibit a wide variety of chemical constituents, the composition of particles found more than two kilometers above the tropopause is dominated by sulfate (Murphy et al., 1998; Kojima et al., 2004). Crutzen (1976) suggested that OCS was likely to be important in maintaining this stratospheric, sulfate layer. Particles and other sulfur-containing gases from the troposphere also play roles but measurements and modeling studies have not resulted in an understanding of their relative contributions (Weisenstein and Bekki, 2006).

\subsection{Circulation, age-of-air and $\mathrm{N}_{2} \mathrm{O}$}

Figure 1 shows the locations of measurements of the nonvolcanic aerosol and the locations of the tropopause sensed while acquiring the entire data set reported here. In the Brewer-Dobson circulation, ascending air enters the stratosphere in the tropics, moves poleward and descends at higher latitudes. Our description of this circulation follows Tuck et al. (1997) and Holton et al. (1995). Outside of the tropics, the lowermost stratosphere is defined as the region between the thermal tropopause and an isentropic surface (surface of constant potential temperature, $\theta$ ) that passes near and above the tropical tropopause. Isentropic surfaces in the lowermost stratosphere are partially in the stratosphere and partially in the troposphere since they cross the tropopause. The overworld lies above the lowermost stratosphere in the extratropics and above the troposphere in the tropics. Isentropic surfaces in the overworld do not cross the tropopause. Most of the air found in the overworld entered the stratosphere in the tropics. Inputs from the extra-tropical troposphere to air having $\theta>390 \mathrm{~K}$ in the stratosphere are insignificant. The isentropic surface separating the overworld and the lowermost stratosphere appears to lie between $360 \mathrm{~K}$ to $400 \mathrm{~K}$ in our data (Fig. 1). This apparent ambiguity is unimportant to our analysis. Air enters the lowermost stratosphere from the troposphere in two-way exchange along isentropes that cross the extra-tropical tropopause. Air also subsides into the lowermost stratosphere from the overworld. The mass of air exchanged between the troposphere and the lowermost stratosphere is larger than the mass entering the lowermost stratosphere by subsidence from the overworld. Most of the observations in the present data set made at mixing ratios of $\mathrm{N}_{2} \mathrm{O}$, $X_{\mathrm{N}_{2} \mathrm{O}}$, greater than $250 \mathrm{ppbv}$ ( $1 \mathrm{ppbv}$ of $\mathrm{N}_{2} \mathrm{O}$ is 1 molecule of $\mathrm{N}_{2} \mathrm{O}$ per $10^{9}$ molecules of air) were sampled in the lowermost stratosphere and most with $X_{\mathrm{N}_{2} \mathrm{O}}<250$ ppbv were sampled in the overworld.

The mean age-of-air equals the average amount of time that the molecules of a conserved tracer have spent in the stratosphere since last leaving the troposphere (Boering et al., 1996). Age-of-air determined from simultaneous airborne measurements of $\mathrm{CO}_{2}, \mathrm{CH}_{4}$ and $\mathrm{N}_{2} \mathrm{O}$ (Andrews et al., 2001) made between March 1997 and April 2000 is plotted against $X_{\mathrm{N}_{2} \mathrm{O}}$ (Fig. 2).

\section{Measurements}

We report measurements of volume mixing ratios of $\mathrm{N}_{2} \mathrm{O}$, OCS and aerosol made from NASA ER-2, WB-57 and DC-8 aircraft in the Northern Hemisphere lower stratosphere from 1992 through January 2004. In addition, we describe measurements of $\mathrm{N}_{2} \mathrm{O}$ and OCS made from balloons between June 1997 and October 2004. The aircraft measurements were made from -5 to $90 \mathrm{~N}$ latitude and the balloon measurements were made between 34 and $68 \mathrm{~N}$ latitude. 


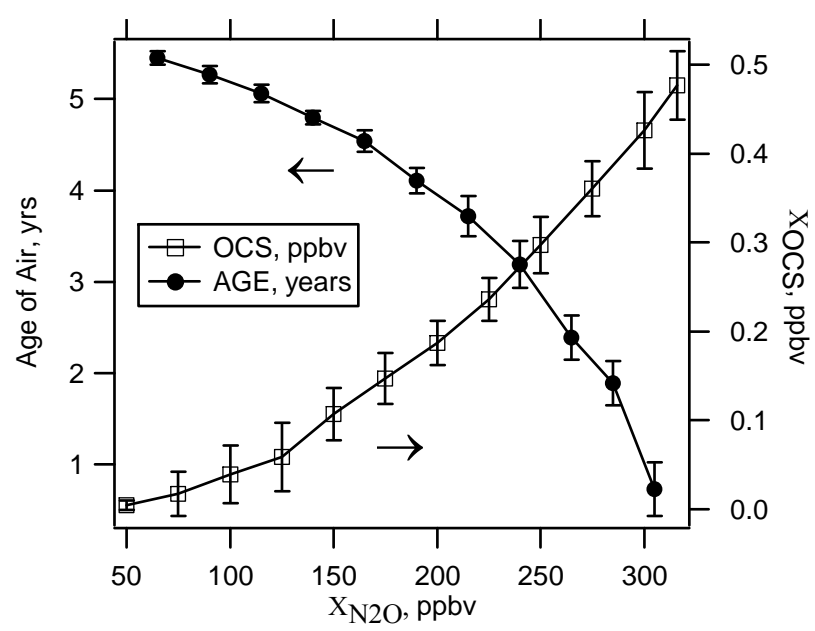

Fig. 2. Age of stratospheric air in years of parcels sampled between March 1997 and April 2000. OCS measured remotely from balloon and sampled from aircraft. Bars indicate plus and minus one standard deviation of the averaged population.

\subsection{Aerosol size distributions}

Focused Cavity Aerosol Spectrometers (FCAS) (Jonsson, et al., 1995) were used to measure aerosol size distributions in the dry diameter range from approximately 100 to $1000 \mathrm{~nm}$. The archived measurements (http://espoarchive. nasa.gov/archive/) are integrated over $30 \mathrm{~s}$, typically include a few thousand particles and extend over a flight path of more than $6 \mathrm{~km}$. The aerosol is warmed during sampling and transport to the laser cavity where individual particles are sized according to the amount of light they scatter. The ambient size is calculated from the measured size, ambient and cavity temperatures and water vapor mixing ratio assuming that the particles are solutions of $\mathrm{H}_{2} \mathrm{SO}_{4}$ and water. Aerosol measurements made between September 1992 and June 1993 contained particles larger than $2 \mu \mathrm{m}$ in diameter and the reported size distributions were constructed from FCAS and Forward Scattering Spectrometer Probe (FSSP) measurements (Wilson et al., 1993).

The FCAS II and FCAS III (Appendix A) were used after 1995 . The FCAS II was tested with nearly 500 nearly monodisperse test aerosols of known diameter and concentration. The median of the absolute values of the discrepancies between the FCAS II and the known diameters was $3 \%$. The median of the absolute values of the discrepancy between the FCAS concentration and the known concentration was $11 \%$. The FCAS III has been tested fewer times and shows similar performance.

The aerosol is sampled with an instrumented, passive, near isokinetic inlet that permits corrections to be made for anisokinetic sampling when it occurs (Jonsson et al., 1995). In many instances, the size distribution was determined from $4 \mathrm{~nm}$ to $2000 \mathrm{~nm}$ by combining information from the FCAS

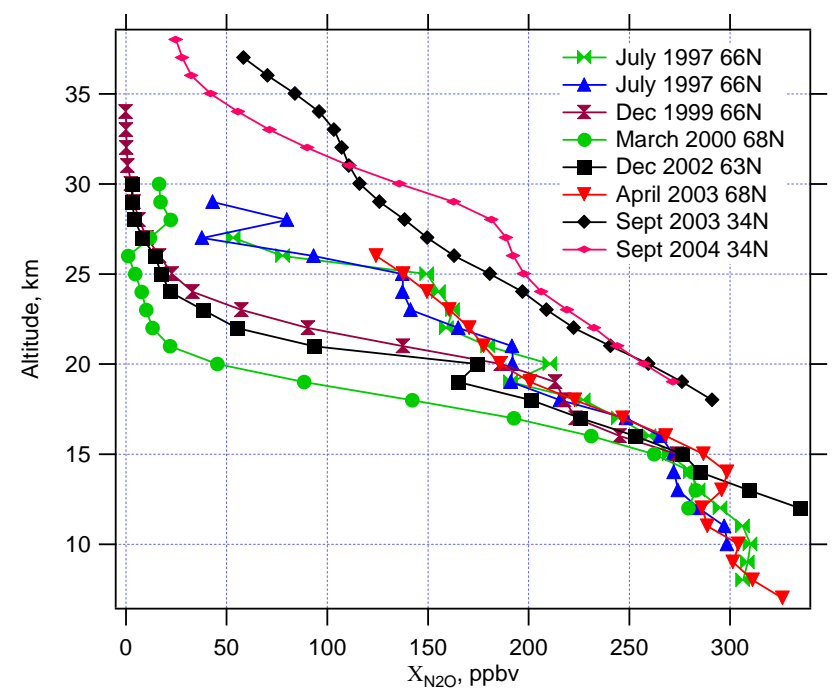

Fig. 3. $\mathrm{N}_{2} \mathrm{O}$ measurements from the balloon-borne Mark IV Interferometer.

and the nuclei mode aerosol spectrometer (NMASS). The NMASS provides 5 size cuts between 4 and $60 \mathrm{~nm}$. These measurements show that the mass on particles smaller than $100 \mathrm{~nm}$ may be neglected for the purposes of this analysis and the NMASS data are not presented here.

These volume distribution measurements differ from other distributions in the literature (Hamill et al., 2006) in that the FCAS resolves particles smaller than $300 \mathrm{~nm}$ in diameter. These particles contribute importantly to the mass distributions in the non-volcanic stratosphere and the data presented here are unique in providing measurements of their abundance.

\subsection{Measurements of gases}

Water vapor, OCS and $\mathrm{N}_{2} \mathrm{O}$ were measured with a variety of techniques (Table 1). Simultaneous aerosol, $\mathrm{N}_{2} \mathrm{O}, \mathrm{H}_{2} \mathrm{O}$ and OCS measurements were made from NASA aircraft. OCS and $\mathrm{N}_{2} \mathrm{O}$ were also sampled on the same flights for later analysis. Simultaneous OCS and $\mathrm{N}_{2} \mathrm{O}$ measurements were made from balloons (Fig. 3).

\section{Results and analysis}

\subsection{Aerosol volume distributions and abundance}

Dry, normalized aerosol volume distributions were sorted into time and $X_{\mathrm{N}_{2} \mathrm{O}}$ intervals (Table 2). The median values of aerosol volume in each diameter interval were used to assemble volume distributions which were then renormalized. These dry distributions (Fig. 4) show the distribution of the non-volatile constituents and do not reflect the variations in the ambient distributions that result from temperature and 
Table 1. Instruments used for gas measurements and the platforms upon which they flew.

\begin{tabular}{llll}
\hline Species & Instrument & Platforms & References \\
\hline $\mathrm{N}_{2} \mathrm{O}$ & $\begin{array}{l}\text { Atlas, Argus, Whole Air } \\
\text { Sampler, DACOM, Panther }\end{array}$ & NASA ER-2 NASA B-57 & Poldolske and Lowenstein, 1993; \\
& & & NASA DC-8 \\
& & & Sachse et al., 1987; \\
& & & Moore et al., 2003; \\
& & Hurst et al., 2002 \\
$\mathrm{H}_{2} \mathrm{O}$ & Harvard Lyman- $\alpha$ Hygrometer & NASA ER-2 NASA B-57 & Hintsa et al., 1999; \\
& JPL Laser Hygrometer & NASA DC-8 & May, 1998; \\
& NASA Langley/Ames Diode & & Poldolske et al., 2003; \\
& Laser Hygrometer & & Diskin et al., 2002 \\
OCS & Whole Air Sampler & NASA ER-2 NASA B-57 & Schauffler et al., 1999 \\
\multirow{2}{*}{$\mathrm{N}_{2} \mathrm{O}$, OCS } & Mark IV Interferometer & Balloon & Toon, 1991 \\
\hline
\end{tabular}

Table 2. Aerosol properties for the volume distributions in Fig. 4: the number of 30 second size distributions, $D_{g v}$, and lognormal fit parameters for the volume distributions: FM1, the fraction of the volume in the smaller mode; $D p_{1}$, the geometric volume mean diameter for the first mode; $S g_{1}$, the geometric standard deviation for the first mode; $D p_{2}$, the geometric volume mean diameter for the second mode; $\mathrm{Sg}_{2}$, the geometric standard deviation for the second mode.

\begin{tabular}{|c|c|c|c|c|c|c|c|}
\hline \multirow[t]{2}{*}{ Interval } & \multicolumn{7}{|c|}{$50 \mathrm{ppbv}<X_{\mathrm{N}_{2} \mathrm{O}}<100 \mathrm{ppbv}$} \\
\hline & Sample size & $D_{g v}, \mu \mathrm{m}$ & FM1 & $D p_{1}, \mu \mathrm{m}$ & $S g_{1}$ & $D p_{2}, \mu \mathrm{m}$ & $\mathrm{Sg}_{2}$ \\
\hline 1 Jun 1996-26 Sep 1997 & 124 & 0.30 & 0.63 & 0.18 & 1.61 & 0.57 & 1.40 \\
\hline 2 Sep 1999-16 Mar 2000 & 1021 & 0.18 & 1.0 & 0.18 & 1.47 & & \\
\hline Interval & \multicolumn{7}{|c|}{$100 \mathrm{ppbv}<X_{\mathrm{N}_{2} \mathrm{O}}<150 \mathrm{ppbv}$} \\
\hline 1 Jun 1996-26 Sep 1997 & 252 & 0.29 & 0.75 & 0.22 & 1.62 & 0.58 & 1.35 \\
\hline 2 Sep 1999-16 Mar 2000 & 2359 & 0.23 & 0.94 & 0.22 & 1.54 & 0.43 & 1.23 \\
\hline Interval & \multicolumn{7}{|c|}{$150 \mathrm{ppbv}<X_{\mathrm{N}_{2} \mathrm{O}}<200 \mathrm{ppbv}$} \\
\hline 1 Jun 1996-26 Sep 1997 & 1960 & 0.35 & 0.78 & 0.29 & 1.64 & 0.65 & 1.28 \\
\hline 2 Sep 1999-16 Mar 2000 & 1937 & 0.27 & 1.0 & 0.27 & 1.61 & & \\
\hline Interval & \multicolumn{7}{|c|}{$200 \mathrm{ppbv}<X_{\mathrm{N}_{2} \mathrm{O}}<250 \mathrm{ppbv}$} \\
\hline 1 Jun 1996-26 Sep 1997 & 9937 & 0.42 & 0.66 & 0.31 & 1.69 & 0.73 & 1.23 \\
\hline 2 Sep 1999-16 Mar 2000 & 1005 & 0.33 & 0.94 & 0.32 & 1.62 & 0.65 & 1.15 \\
\hline Interval & \multicolumn{7}{|c|}{$250 \mathrm{ppbv}<X_{\mathrm{N}_{2} \mathrm{O}}<300 \mathrm{ppbv}$} \\
\hline 1 Jun 1996-26 Sep 1997 & 4143 & 0.44 & 0.56 & 0.26 & 1.70 & 0.78 & 1.25 \\
\hline 2 Sep 1999-16 Mar 2000 & 2061 & 0.31 & 0.63 & 0.22 & 1.44 & 0.51 & 1.40 \\
\hline 12 Dec 2002-7 Feb 2003 & 994 & 0.27 & 0.63 & 0.19 & 1.43 & 0.46 & 1.63 \\
\hline 16 Jan 2004-30 Jan 2004 & 104 & 0.29 & 0.64 & 0.21 & 1.49 & 0.46 & 1.54 \\
\hline
\end{tabular}

water vapor changes. The mean of the ratio of ambient to dry diameter for these data is 1.30 with a standard deviation of 0.1 .

The volume distributions observed in 1992-1993 were heavily perturbed by the eruption of Mt. Pinatubo. The distributions seen in 1996-1997 clearly show the lingering impact of the volcanic aerosol and therefore these distribu- tions are not included in the analysis of the steady state. For $X_{\mathrm{N}_{2} \mathrm{O}}>100 \mathrm{ppbv}$, larger particles are more evident at larger values of $X_{\mathrm{N}_{2} \mathrm{O}}$ which are encountered at lower altitudes (Fig. 3). The geometric volume mean diameters (Appendix B) for distributions measured in 1996-1997 exceed those measured after 1999 at the same values of $X_{\mathrm{N}_{2} \mathrm{O}}$ (Table 2). Accurate, bimodal, lognormal fits (Appendix B) to the 


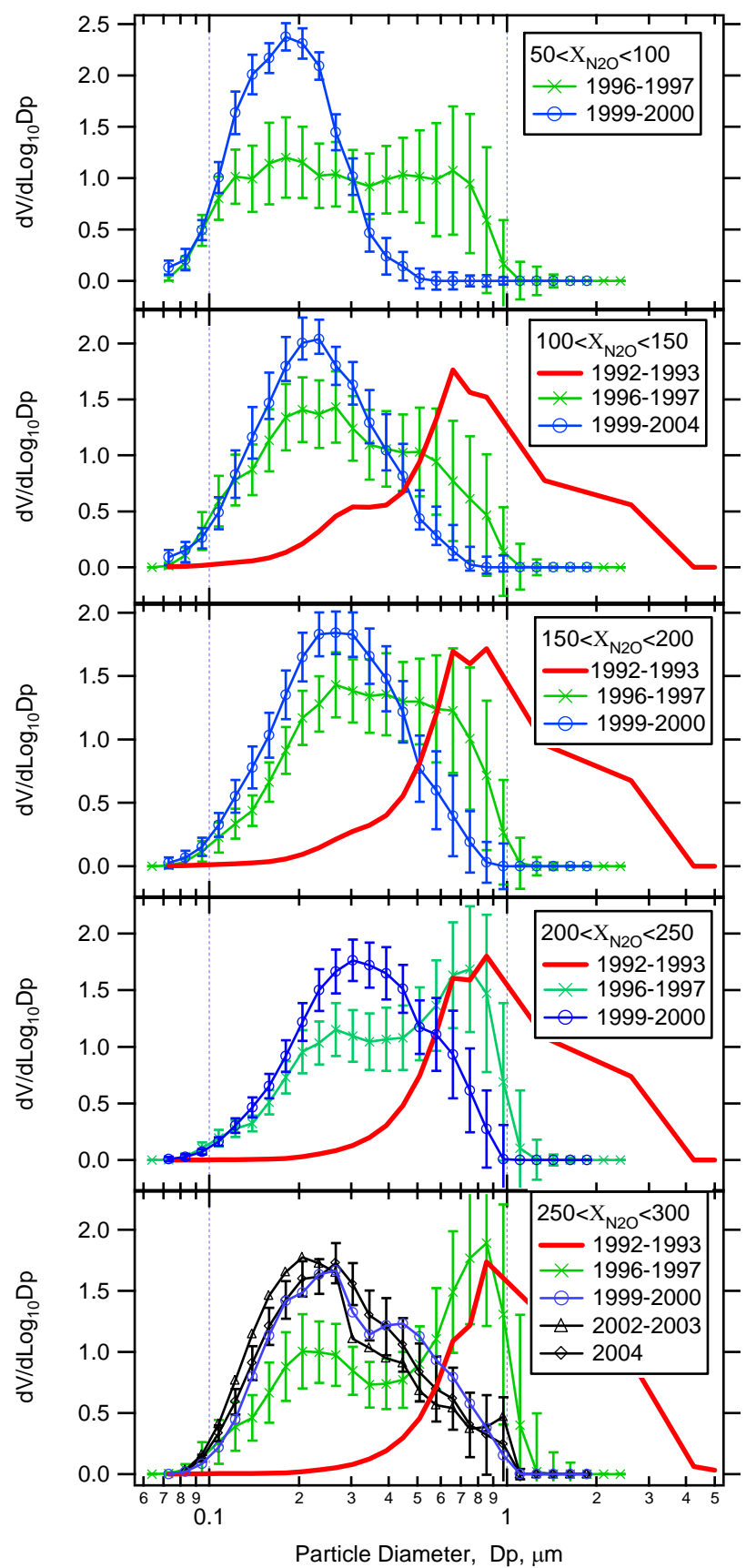

Fig. 4. Normalized aerosol volume distributions for intervals of $X_{\mathrm{N}_{2} \mathrm{O}}$ and time intervals defined in Table 2. Bars indicate plus and minus one standard deviation of the population used to determine the median.

distributions measured after 1999 and with $X_{\mathrm{N}_{2} \mathrm{O}}<250 \mathrm{ppbv}$ are dominated by a single mode whose geometric volume mean diameter increases with $X_{\mathrm{N}_{2} \mathrm{O}}$ (Table 2). For all the 1996-1997 distributions and the post-1999 distributions with $X_{\mathrm{N}_{2} \mathrm{O}}>250$, the volume distribution required two modes to produce an accurate fit to particles larger than $100 \mathrm{~nm}$. Num-

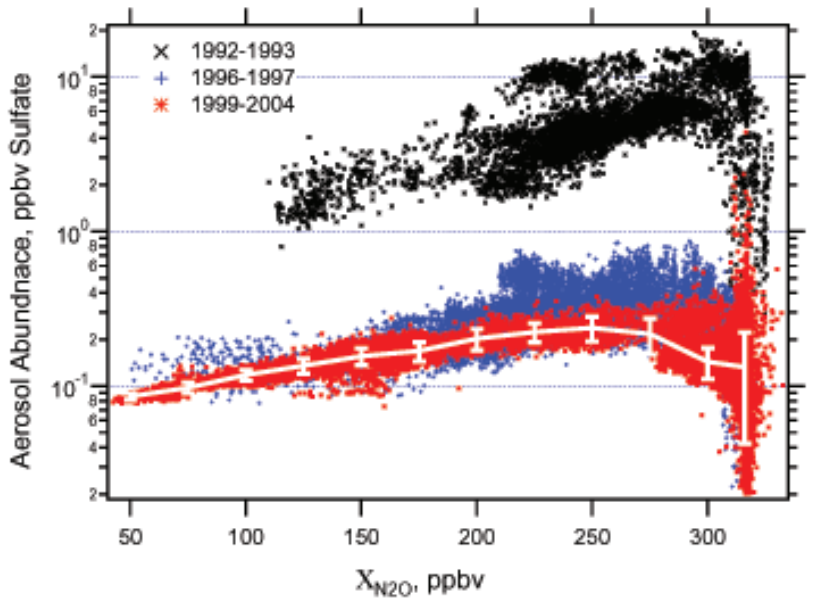

Fig. 5. Aerosol abundance in ppbv aerosol sulfate for the steadystate (1999-2004), the volcanically enhanced (1992-1993) and the transition (1996-1997) observations. One ppbv of aerosol sulfate is one molecule of aerosol sulfate per $10^{9}$ molecules air. The error bars encompass plus and minus one standard deviation of the measurements grouped to produce the line that summarizes the steadystate observations.

ber distributions extending below $100 \mathrm{~nm}$ may require more modes for accurate characterization. Measured number distributions of these smaller particles show that this is certainly the case for $X_{\mathrm{N}_{2} \mathrm{O}}>250 \mathrm{ppbv}$.

In 1992-1993 and 1996-1997, the scatter of aerosol abundance at values of $X_{\mathrm{N}_{2} \mathrm{O}}>225 \mathrm{ppbv}$ is much larger than the scatter seen after 1999 (Fig. 5). The larger scatter likely resulted from the non-uniformity of the volcanic injection and subsequent mixing (Hamill and Brogniez, 2006). The decrease in aerosol abundance with $X_{\mathrm{N}_{2} \mathrm{O}}$ below $250 \mathrm{ppbv}$ for all three time periods is likely due in part to the increase in sedimentation speed as pressure decreases. The abundance of the 1992-1993 aerosol greatly exceeds that seen in 19961997 and after 1999. After 1999, the volume mixing ratio of the sulfate aerosol decreases nearly monotonically with $X_{\mathrm{N}_{2} \mathrm{O}}$ for $X_{\mathrm{N}_{2} \mathrm{O}}<250$ ppbv (Figs. 5, 6) and in this region, the scatter in abundance at a given value of $X_{\mathrm{N}_{2} \mathrm{O}}$ is smaller than seen with the volcanic aerosol.

3.2 Steady state distributions and abundances in nonvolcanic, stratospheric aerosol

\subsubsection{Utility of $X_{\mathrm{N}_{2} \mathrm{O}}$ as the independent coordinate}

Age-of-air, or $X_{\mathrm{N}_{2} \mathrm{O}}$ as its surrogate, is a useful coordinate for describing the non-volcanic, stratospheric aerosol since the processes involving aerosol particles proceed in an orderly way with time and the residence times are long (Figs. 1, 2). Stratospheric particles may be included in polar stratospheric clouds (PSCs), but we found that these cloud events do not noticeably redistribute sulfate aerosol mass even in 


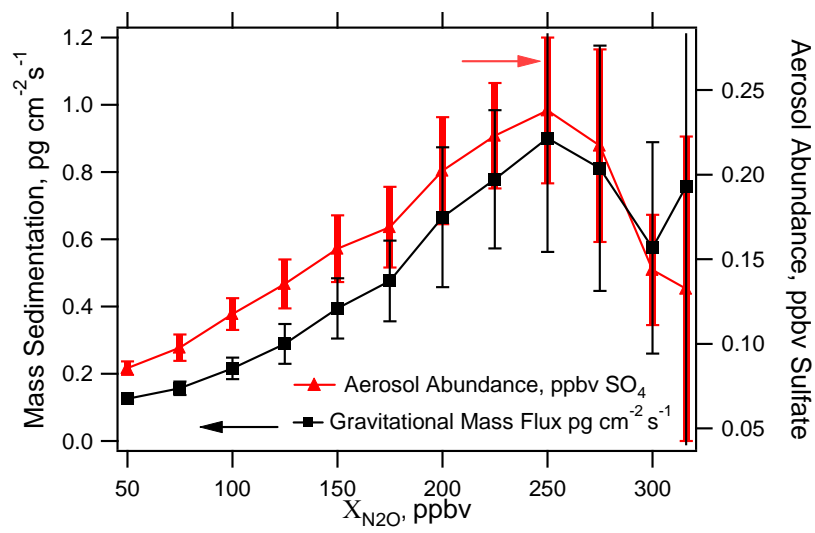

Fig. 6. Gravitational sedimentation rate in picograms per square centimeter per second. Sedimentation was calculated with ambient diameters and densities. Aerosol abundance expressed as parts per billion by volume aerosol sulfate. The error bars indicate plus and minus one standard deviation of the data grouped to get the point. Measurements made after August 1999.

cases where PSCs transported reactive nitrogen downward. We compared air parcels which had been denitrified by PSCs with non-denitrified air having the same values of $X_{\mathrm{N}_{2} \mathrm{O}}$. The sulfate loadings were very similar in the two populations. So, measurements in denitrified air were not excluded from this analysis.

Sorting aerosol distributions and abundance based on $X_{\mathrm{N}_{2} \mathrm{O}}$ groups similar samples and distinguishes among dissimilar ones. The shapes of the size distributions are clearly dependent on $X_{\mathrm{N}_{2} \mathrm{O}}$ (Fig. 4). There is little overlap of the one sigma error bars for the distributions grouped by $X_{\mathrm{N}_{2} \mathrm{O}}$ for $X_{\mathrm{N}_{2} \mathrm{O}}<250 \mathrm{ppb}$. Variance of aerosol abundance is reduced when samples are grouped by $X_{\mathrm{N}_{2} \mathrm{O}}$. The standard deviations of similar sized samples of aerosol mixing ratios were larger by up to $50 \%$ when the samples were defined in terms of latitude and altitude than when they were defined in terms of $X_{\mathrm{N}_{2} \mathrm{O}}$.

\subsubsection{Sedimentation and gas-to-particle formation in the overworld}

The abundance and volume distributions of the stratospheric aerosol evolve as the air ages (Figs. 4, 5, 6). In a steady state, the aerosol properties are similar in air parcels having the same age-of-air and $X_{\mathrm{N}_{2} \mathrm{O}}$. For $X_{\mathrm{N}_{2} \mathrm{O}}<250 \mathrm{ppbv}$, aerosol properties were measured in the interval from September 1999 to March 2000. These observations do not extend over sufficient time to demonstrate that the relationships between aerosol properties and $X_{\mathrm{N}_{2} \mathrm{O}}$ were unchanging. However, aerosol processes controlling abundance were evaluated and the rates of formation, sedimentation and change in aerosol abundance are consistent with the maintenance of a steady state.

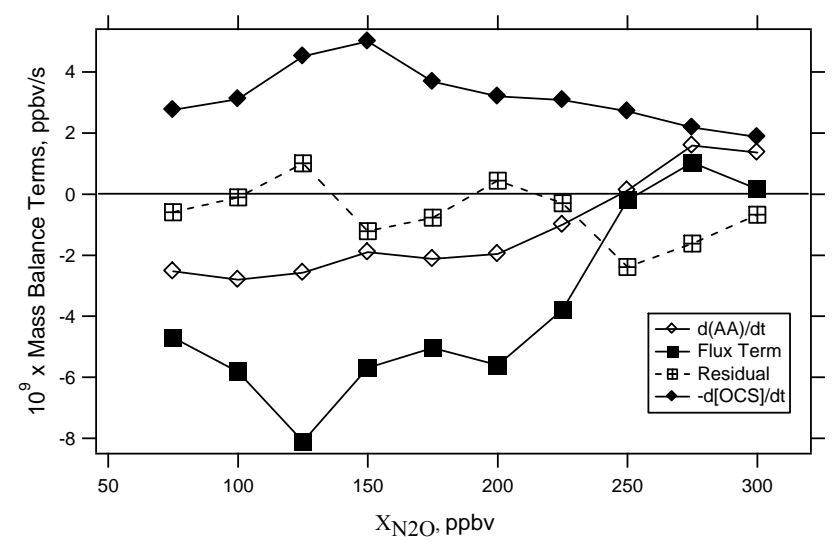

Fig. 7. Observed rate of change of aerosol abundance, $d(A A) / d t$, the net gravitational flux of aerosol into each control volume, the residual term (Eq. 1), and the negative of the OCS loss rate, $d(\mathrm{OCS}) / d t$. Conversion of OCS to aerosol and sedimentation explain the observed time rate of change of aerosol abundance, $A A$, for $X_{\mathrm{N}_{2} \mathrm{O}}<225$.

The rate of sedimentation was calculated with ambient sizes and densities and found to depend upon $X_{\mathrm{N}_{2} \mathrm{O}}$ (Fig. 6). Control volumes were defined with upper and lower surfaces differing by $50 \mathrm{ppbv}$ in $X_{\mathrm{N}_{2} \mathrm{O}}$. Equation 1 describes the rate of change in aerosol abundance, $A A$ ppbv aerosol sulfur, in each control volume. (One ppbv of aerosol sulfur is one atom of sulfur in the aerosol per $10^{9}$ molecules of air. When the sulfur in one ppbv of OCS is converted from gas to aerosol, it creates 1 ppbv of aerosol sulfur.)

$$
\frac{d A A}{d t}=-\frac{d X_{\mathrm{OCS}}}{d t}+\frac{0.302 \times 10^{9} \cdot\left(\text { Flux }_{\text {in }}-\text { Flux }_{\text {out }}\right) \cdot g}{\Delta P}+R
$$

The time derivatives of $A A$ and $X_{\mathrm{OCS}}$ are the products of their respective derivatives with respect to $X_{\mathrm{N}_{2} \mathrm{O}}$ (Figs. 6, 2) and the derivative of $X_{\mathrm{N}_{2} \mathrm{O}}$ with respect to time (Fig. 2). The sulfur in OCS ends up in the aerosol and the destruction of OCS is the slowest step in the process thus its derivative appears in Eq. 1. Flux ${ }_{i n}$ and Flux $x_{\text {out }}$ are the aerosol mass fluxes due to gravitational sedimentation. Flux $x_{\text {in }}$ equals the flux through the surface with smaller $X_{\mathrm{N}_{2} \mathrm{O}}$ which is at the higher altitude (Fig. 3). Flux ${ }_{\text {out }}$ equals the flux through the surface with larger $X_{\mathrm{N}_{2} \mathrm{O}} . \Delta P$ is the difference in ambient static pressure between the bounding $\mathrm{N}_{2} \mathrm{O}$ surfaces and $\mathrm{g}$ is the acceleration due to gravity. The remaining terms convert from mass to volume mixing ratios for $\mathrm{H}_{2} \mathrm{SO}_{4}$ aerosol. The residual, $R$, represents the contribution to $d A A / d t$ that is not explained by sedimentation and conversion of OCS. For each $\mathrm{N}_{2} \mathrm{O}$ interval, an average $\Delta P$ was determined from the aircraft data set and a second one was determined from the balloon soundings. The average of these two averages was used to calculate the flux terms and the residual terms (Fig. 7). 
For $225>X_{\mathrm{N}_{2} \mathrm{O}}>75, A A$ decreases with time and $X_{\mathrm{N}_{2} \mathrm{O}}$. $R$ is much smaller than the time derivatives and sedimentation terms and oscillates around zero. Thus the mass sedimentation rates that result from the observed size distributions and the observed time derivatives of $X_{\mathrm{OCS}}$ combine to explain the observed time derivatives of $A A$ (Fig. 7). The balance holds in each of these control volumes. To estimate the amount of aerosol sulfur processed in a year, we multiplied the OCS time derivative and the sedimentation term in Eq. 1 by the number of seconds in a year and found that for $X_{\mathrm{N}_{2} \mathrm{O}}<200 \mathrm{ppbv}$, the amount of sulfur condensed or sedimented out per year roughly equals the steady state abundance.

A near-zero value for $R$ in Eq. 1 is consistent with a steady state in the overworld as long as mixing across $\mathrm{N}_{2} \mathrm{O}$ surfaces, precursor gases apart from OCS, meteoric debris and changing boundary conditions do not alter the described processes. Mixing terms are not included in Eq. 1, but OCS and $A A$ are nearly linear with $X_{\mathrm{N}_{2} 0}$ (Figs. 2, 6) over large segments of the $X_{\mathrm{N}_{2} 0}$ range for $X_{\mathrm{N}_{2} 0}<250 \mathrm{ppbv}$. Thus mixing across $\mathrm{N}_{2} \mathrm{O}$ surfaces does not change the analysis as long as the mixed air does not come from extreme ends of the range. Air with $X_{\mathrm{N}_{2} 0}<250 \mathrm{ppbv}$ has been in the stratosphere for more than 2.8 years on average. Other known precursor gases are short-lived (Notholt and Bingemer, 2006) and are not likely to contribute noticeably to $d A A / d t$ in this region. Thus, the contribution of OCS is likely to dominate gas-to-particle conversion as is implied in the equation. Neglecting meteoric debris certainly means that elemental diversity will be slighted, but not much aerosol mass will be missed (Murphy et al., 1998). Lastly, this aerosol was measured after September 1999, north of $40 \mathrm{~N}$ at $\theta>390 \mathrm{~K}$ (Fig. 1). For the steady state to exist, the aerosol and precursor gases entering the region must not change. The satellite records of extinction at 1.02 micron wavelengths (Hamill and Brogniez, 2006) suggest that these are reasonable assumptions for the period after September 1999. This analysis provides a unique empirical link between the aerosol distributions and OCS abundance in the steady state and supports the conclusion from modeling that in this region OCS is the primary precursor gas (Weisenstein and Bekki, 2006).

\subsubsection{Extra-tropical, lowermost stratosphere}

Most measurements made with $300>X_{\mathrm{N}_{2} \mathrm{O}}>250$ ppbv were made in the extra-tropics at $\theta<390 \mathrm{~K}$ in the lowermost stratosphere. The similarity of the volume distributions measured at three different times after September 1999 supports the existence of a steady state (Fig. 4). The terms for Eq. 1 are informative here as well. $A A$ increases with time at a rate that is smaller than the conversion rate of OCS (Fig. 7). The variabilities in the aerosol properties and gravitational flux are larger (Fig. 6), and the magnitudes of the derivatives and net flux are small and on the order of the residual term (Fig. 7). The sign of the net gravitational flux may be uncer- tain. In this region, the residual term must include exchange with the upper troposphere and conversion of precursor gases other than OCS. For example, approximately $40 \mathrm{pptv}$ of $\mathrm{SO}_{2}$ is routinely encountered in this region (Lee et al., 2003). The shape of the median volume distribution in the upper troposphere is similar to that in the lowermost stratosphere but the particles are smaller and the mass abundance is less. The aerosol abundance measurements in the upper troposphere and lowermost stratosphere suggest that exchange of air between the regions will reduce the aerosol abundance in the lower stratosphere. Exchange then is consistent with the need to remove some of the aerosol formed by gas-to-particle conversion in order to predict $d A A / d t$. Due to the more varied aerosol chemistry near the tropopause, $A A$ likely includes substances other than sulfate.

\subsection{Implications for modeling the stratospheric aerosol}

Recent model calculations of aerosol properties have been compared to measurements of ambient aerosol properties for the non-volcanic stratosphere (Weisenstein and Bekki, 2006). The authors state a lack of confidence in the ability to model sulfur below $20 \mathrm{~km}$ altitude. They acknowledge that transport is a major uncertainty, and that models predict shorter mean ages for the stratospheric air than are suggested by observations. Most of the models over-estimate optical extinctions at $0.525 \mu \mathrm{m}$ and $1.02 \mu \mathrm{m}$ between 15 and $20 \mathrm{~km}$ in the profiles at $45 \mathrm{~N}$. Optical depths at these wavelengths are also often overestimated in the Northern Hemisphere in this altitude range. Three of the five models over-predicted OCS at $65 \mathrm{~N}$ in nearly the same altitude range. Of the published comparisons, these are the most relevant to the data and analysis presented above as they address both aerosol abundance and OCS in the altitude and latitude range covered by our measurements.

For $X_{\mathrm{N}_{2} \mathrm{O}}<250 \mathrm{ppbv}$, both the abundance of aerosol and $X_{\text {ocs }}$ decrease as age-of-air increases (Figs. 2, 6). This suggests that the reported discrepancies between measured and modeled extinction, optical depth and $X_{\text {ocs }}$ could be reduced by transport schemes that increased the mean stratospheric age-of-air arriving at the comparison points. For example from Figs. 2 and 6, adding one year to the age of air with $X_{\mathrm{N}_{2} \mathrm{O}}$ of $250 \mathrm{ppbv}$ reduces the OCS by about $33 \%$ and the aerosol abundance by about $17 \%$. This would slightly over correct the three most discrepant OCS model predictions at $18 \mathrm{~km}, 67 \mathrm{~N}$ in July and slightly under correct the four most discrepant extinction model predictions at $65 \mathrm{~N}, 18 \mathrm{~km}$ in July as reported by Weisenstein and Bekki (2006). Adding one year is a significant change. Although this region of the stratosphere is small in terms of altitude range, it does contain substantial amounts of aerosol in both the perturbed and steady states (Fig. 5). Improvements in model predictions of the transport and mixing of air in this region are likely to improve model predictions of the impact of anthropogenic perturbations of the stratospheric aerosol aimed at 
balancing green house gas emissions. We do not address the reported comparisons between the satellite-derived aerosol surface area concentrations and the models presented in the reference because the satellite-derived surface values are in error.

\section{Appendix A}

\section{Focused Cavity Aerosol Spectrometer II and III}

The FCAS II has been calibrated with over 490 test aerosols generated with an atomizer and classified with a differential mobility analyzer (DMA). The concentration of the classified calibration aerosol was determined with a low pressure condensation nucleus counter (CNC) (Wilson et al, 1983) and its refractive index is near to that of $\mathrm{H}_{2} \mathrm{SO}_{4}$-water solutions found in the stratosphere. Calibrations were carried out at the pressures at which the instrument is operated. The data reduction procedure involves an inversion of the response matrix determined from the calibrations with the nearly monodisperse DMA aerosol. A new response matrix was generated every time one of the critical optical components was replaced. The matrices have 31 rows. The number of columns varied from 28 to 31 , with one column for each particle size used to span the instrument's range. The matrix elements equal the fraction of the particles of a given size (column) whose scattered intensity fell in the channel (row). Counts from multiply charged particles exiting the DMA are removed from the matrix. The data reduction method (Markowski, 1987) involves a Twomey method matrix inversion since the response matrix is not diagonal. The detection efficiency is a function of pressure and particle size and is taken into account in data reduction.

The FCAS III has similar optics and calibration techniques to the FCAS II. The responses and uncertainties of the instruments are similar in the laboratory. The instruments have different mounting arrangements, and we conclude that particles were not dried thoroughly in the FCAS III around the tropopause in 1999-2000 where temperature regulation was most difficult. Comparisons with solar occultation satellite measurements show that the over estimation of particle size caused by incomplete drying in the FCAS III decreased with altitude. The errors are within the calibration uncertainties at altitudes higher than $16 \mathrm{~km}$. Thus, this problem does not impact the bulk of the FCAS III measurements which were made above $16 \mathrm{~km}$ and at $\left[\mathrm{N}_{2} \mathrm{O}\right]<250$.

\section{Appendix B}

\section{Parameters describing the distributions}

The dry distributions were fit with Eq. B1. $d V_{\text {norm }}$ is the volume between $D p$ and $D p+d D p$.

$\frac{d V_{\text {norm }}}{d \log _{10} D p}=\frac{\text { FM1 }}{\sqrt{2 \pi} \log _{10}\left(S g_{1}\right)}$
$\exp \left[\frac{-\ln ^{2}\left(D p / D p_{1}\right)}{2 \ln ^{2}\left(S g_{1}\right)}\right]+\frac{(1-\mathrm{FM} 1)}{\sqrt{2 \pi} \log _{10}\left(S g_{2}\right)} \exp \left[\frac{-\ln ^{2}\left(D p / D p_{2}\right)}{2 \ln ^{2}\left(S g_{2}\right)}\right]$

FM1 is the fraction of the volume in the first or smaller mode. $D p_{1}$ is the geometric volume mean diameter of the first mode and $S g_{1}$ is the geometric standard deviation of that mode. $D p_{2}$ and $S g_{2}$ describe the second mode.

The geometric volume mean diameter, $D_{g v}$, of each distribution was calculated with Eq. B2 where $\Delta V_{k}$ is the volume in the $k$ th size interval which is characterized by the diameter $D p_{k}$.

$\ln \left(D_{g v}\right)=\frac{\sum_{k=1}^{31} \Delta V_{k} \cdot \ln \left(D p_{k}\right)}{\sum_{k=1}^{31} \Delta V_{k}}$

Acknowledgements. JCW gratefully acknowledges useful conversations of A. Tuck, K. Rosenlof, D. Weisenstein, S. Wofsy and J. Elkins and comments of two anonymous reviewers. In situ measurements were made from NASA research aircraft and remote measurements were made from balloons with sponsorship of the NASA Upper Atmosphere Research Program, the NASA Atmospheric Effects of Aviation Project, and the NASA Radiation Sciences Program.

Edited by: S. Martin

\section{References}

Andrews, A. E., Boering, K. A., Daube, B. C., Wofsy S. C., Loewenstein, M., Jost, H., Podolske, J. R., Webster, C. R., Herman, R. L., Scott, D. C., Flesch, G. J., Moyer, E. J., Elkins, J. W., Dutton, G. S., Hurst, D. F., Moore, F. L., Ray, E. A., Romashkin, P. A., and Strahan, S. E.: Mean ages of stratospheric air derived from in situ observations of $\mathrm{CO}_{2}, \mathrm{CH}_{4}$, and $\mathrm{N}_{2} \mathrm{O}$, J. Geophys. Res., 106, 32 295-32 314, 2001.

Boering, K. A., Wofsy, S. C., Daube, B. C., Schneider, H. R., Loewenstein, M., Podolske, J. R., and Conway, T. J.: Stratospheric mean ages and transport rates from observations of carbon dioxide and nitrous oxide, Science, 274, 1340-1343, 1996.

Crutzen, P.: The possible importance of CSO for the sulfate layer of the stratosphere, Geophys. Res. Lett., 3, 73-76, 1976.

Deshler, T. and Anderson-Sprecher, R.: Ch 5. Non-volcanic stratospheric aerosol trends: 1971-2004 in: Sparc Assessment of Stratospheric Aerosol Properties, edited by: Thomason, L. and Peter, T., World Climate Research Program 124, Toronto, 177218, 2006. 
Diskin, G. S., Podolske, J. R., Sachse, G. W., and Slate, T. A.: Open-Path Airborne Tunable Diode Laser Hygrometer, in: Diode Lasers and Applications in Atmospheric Sensing, SPIE Proceedings, 4817, edited by: Fried, A., 196-204, 2002.

Fahey, D. W., Kawa, S. R., Woodbridge, E. L., Tin, P., Wilson, J. C., Jonsson, H. H., Dye, J. E., Baumgardner, D., Borrmann, S., Toohey, D. W., Avalone, L. M., Proffitt, M. H., Margitan,J., Loewenstein, M., Podolske,J. R., Salawitch, R. J., Wofsy,S. C., Ko, M. K. W., Anderson, D. E., Schoeberl, M. R., and Chan, K. K.: In situ measurements constraining the role of sulphate aerosols in mid-latitude ozone depletion, Nature, 363, 509-514, 1993.

Hamill, P. and Brogniez, C.: Ch 4. Stratospheric aerosol record and climatology, in: SPARC Assessment of Stratospheric Aerosol Properties, edited by: Thomason, L. and Peter, T., World Climate Research Program 124, Toronto, 107-176, 2006.

Hamill, P., Brogniez, C., Thomason, L., and Deshler, T.: Ch 3. Instrument descriptions, in SPARC Assessment of Stratospheric Aerosol Properties, edited by: Thomason, L. and Peter, T., World Climate Research Program 124, Toronto, 77-106, 2006.

Hamill, P., Jensen, E. J., Russell, P. B., and Bauman, J. J.: The life cycle of stratospheric aerosol particles, Bull. Amer. Met. Soc., 78, 1395-1410, 1997.

Hintsa, E. J., Weinstock, E. M., Anderson, J. G., May, R. D., and Hurst, D. F.: On the accuracy of in situ water vapor measurements in the troposphere and lower stratosphere with the Harvard Lyman-alpha hygrometer, J. Geophys. Res., 104(D7), 8183-8190, doi:10.1029/1998JD100110, 1999.

Holton, J. R., Haynes, P. H., McIntyre, M. E., Douglass, A. R., Rood, R. B., and Pfister, L.: Stratosphere-troposphere exchange, Rev. Geophys., 33(4), 403-440, 1995.

Hurst, D. F., Schauffler, S. M., Greenblatt, J. M, Jost, H., Herman, R. L., Elkins, J. W., Romashkin, P. A., Atlas, E. L., Donnelly, S. G., Podolske, J. R., Loewenstein, M., Webster, C. R., Flesch, G. J., and Scott, D., C.: Construction of a unified, high-resolution nitrous oxide data set for ER-2 flights during SOLVE, J. Geophys. Res., 107(D20), 8271, doi:10.1029/2001JD000417, 2002.

Jonsson, H. H., Wilson, J. C., Brock C. A., Knollenberg, R. G., Newton, R., Dye, J. E., Baumgardner, D., Borrmann, S., Ferry, G. V., Pueschel, R., Woods, D. C., and Pitts, M. C.: Performance of a focused cavity aerosol spectrometer for measurements in the stratosphere of particle size in the 0.06-2.0 $\mu \mathrm{m}$ Diameter Range, J. Ocean. Atmos. Technol., 12, 115-129, 1995.

Kojima, T., Buseck, P. R., Wilson, J. C., and Reeves, J. M.: Aerosol particles from tropical convective systems: cloud tops and cirrus anvils, J. Geophys. Res., 109, D12201, doi:10.1029/2003JD004504, 2004

Lee, S.-H., Reeves, J. M., Wilson, J. C., Hunton, D.E., Viggiano, A. A., Miller, T. M., Ballethin, J. O., Lait, L. R.: Particle formation by ion nucleation in the upper troposphere and lower stratosphere, Science, 301, 1886-1889, 2003.

Markowski, G. R.: Improving the Twomey algorithm for inversion of aerosol measurement data, Aerosol Sci. Tech., 7, 127-141, 1998.

May, R. D.: Open-path, near-infrared tunable diode laser spectrometer for atmospheric measurements of $\mathrm{H}_{2} \mathrm{O}$, J. Geophys. Res., 103(D15), 19 161-19 172, 1998.

Moore, F. L., Elkins, J. W., Ray, E. A., Dutton, G. S., Dunn, R. E., Fahey, D. W., McLaughlin, R., J., Thompson, T. L., Ro- mashkin, P. A., Hurst, D. F. and Wamsley, P. R.: Balloonborne in situ gas chromatograph for measurements in the troposphere and stratosphere, J. Geophys. Res., 108(D5), 8330, doi:10.1029/2001JD000891, 2003.

Murphy, D. M., Thompson, D. S., and Mahoney M., J.: In Situ Measurements of organics, meteoritic material, mercury, and other elements in aerosols at 5 to 19 kilometers, Science, 282, 16641669, 1998.

Notholt, J. and Bingemer, H.: Ch 2. Precursor gas measurements, in: SPARC Assessment of Stratospheric Aerosol Properties, edited by: Thomason, L. and Peter, T., World Climate Research Program 124, Toronto, 29-76, 2006.

Oberbeck, V. R., Danielsen, E. F., Snetsinger, K. G., Ferry, G. V., Fong, W., and Hayes, D., M.: Effect of the eruption of El Chichon on stratospheric aerosol size and composition, Geophys. Res. Lett., 10(11), 1021-1024, 1983.

Podolske, J. and Loewenstein, M.: Airborne tunable diode laser for airborne trace gas measurements in the lower stratosphere, Appl. Opt., 32, 5324-5347, 1993.

Podolske, J. R., Sachse, G. W., and Diskin, G. S.: Calibration and Data Retrieval Algorithms for the NASA Langley/Ames Diode Laser Hygrometer for the NASA TRACE-P Mission, J. Geophys. Res., 108(D20), 8792, doi:10.1029/2002JD003156, 2003.

Sachse, G. W., Hill, G. F., Wade, L. O., and Perry, M. G.: Fastresponse, high-precision carbon monoxide sensor using a tunable diode laser absorption technique, J. Geophys. Res., 92, 20712081, 1987.

Schauffler, S. M., Atlas, E. L., Blake, D. R., Flocke, F., Lueb, R. A., Lee-Taylor, J. M., Stroud, V., and Travnicek, W.: Distributions of brominated organic compounds in the troposphere and lower stratosphere, J. Geophys. Res., 104(D17), 21 513-21 535, 1999.

Sheridan, P. J., Schnell, R. C., Hofmann, D. J., and Deshler, T.: Electron microscope studies of Mt. Pinatubo aerosol layers over Laramie, Wyoming during summer, Geophys. Res. Lett., 19(2), 203-206, doi:10.1029/91GL02789, 1992.

Sheridan, P. J., Brock, C. A., and Wilson J. C.: Aerosol particles in the upper troposphere and lower stratosphere: Elemental composition and morphology of individual particles in northern midlatitudes, Geophys. Res. Lett., 21, 2587-2590, 1994.

Solomon, S., Portmann, R. W., Garcia, R. R., Thomason, L. W., Poole, L. R., and McCormick, M. P.: The role of aerosol variations in anthropogenic ozone depletion at northern midlatitudes, J. Geophys. Res., 101(D3), 6713-6728, 1996.

Toon, G. C.: The MkIV Interferometer, Opt. Photonics News, 2, 19-21, 1991.

Tuck, A. F., Baumgarder, D., Chan, K. R., Dye, J. E., Elkins, J. W., Hovde, S. J., Kelly, K. K., Loewensein, M., Margitan, J. J., May, R. D., Podolske, J. R., Profitt, M. H., Rosenlof, K. H., Smith W. L., Webster, C. R., and Wilson, J. C.: The BrewerDobson circulation in the light of high altitude in situ aircraft observations, Q. J. R. Meteorol. Soc., 123, 1-63, 1997.

Wennberg, P. O., Cohen, R. C., Stimpfle, R. M., Koplow, J. P., Anderson, J. G., Salawitch, R. J., Fahey, D. W., Woodbridge, E. L., Keim, E. R., Gao, R. S., Webster, C. R., May, R. D., Toohey, D. W., Avallone, L. M., Proffitt, M. H., Loewenstein, M., Podolske, J. R., Chan, K. R., and Wofsy, S. C.: Removal of Stratospheric $\mathrm{O}_{3}$ by Radicals: In Situ Measurements of $\mathrm{OH}, \mathrm{HO}_{2}, \mathrm{NO}, \mathrm{NO}_{2}$, CLO and BrO, Science, 266, 398-404, 1994.

Wigley, T. M. L.: A combined mitigation/geoengineering approach 
to climate stabilization, Science, 314, 452-454, 2006.

Weisenstein, D. and Bekki, S.: Ch 6. Modeling, in SPARC Assessment of Stratospheric Aerosol Properties, edited by: Thomason, L. and Peter, T., World Climate Research Program 124, Toronto, 219-271, 2006.

Wilson, J. C., Jonsson, H. H., Brock, C. A., Toohey, D. W., Avalone, L. M., Baumgardner, D., Dye, J., E., Poole, L. R., Woods,
D. C., DeCoursey, R. J., Osborne, M., Pitts, M. C., Kelly, K. K., Chan, K. R., Ferry, G. V., Loewenstein, M., Podolske, J. R., and Weaver, S.: In situ observations of aerosol and chlorine monoxide after the 1991 eruption of Mount Pinatubo: effect of reactions on sulfate aerosol, Science, 261, 1140-1143, 1993. 